\title{
NONGONOCOCCAL URETHRITIS
}

\author{
BARRY A. KOGAN, M.D. \\ From the Section of Urology, Department of Surgery, \\ University of Michigan Medical Center, \\ Ann Arbor, Michigan
}

\begin{abstract}
Nongonococcal urethritis is a venereal disease whose incidence is almost double that of gonorrhea. Despite this, the diagnosis, origin, treatment, and complications of nongonococcal urethritis remain unclear. Although some cases are undoubtedly caused by infection with Chlamydia trachomatis, the origin of many cases is uncertain. Treatment is recommended to shorten symptoms and prevent complications. This review presents the current status of this confusing disease.
\end{abstract}

Urethritis, or inflammation of the urethra, may be secondary to infection, trauma, allergy, foreign body, or an as yet undetermined factor. An inlying urethral catheter is a well-recognized cause. Likewise, infection with Neisseria gonorrhoeae often involves the urethra and is usually diagnosed and treated easily. The cause of most other cases of urethritis is more subtle, and in the past these cases have been grouped together as nonspecific urethritis. The term nongonococcal urethritis applies to exactly the same entity, yet is more descriptive and, therefore, preferable. The diagnosis is made only in men since the symptoms, and, therefore, the clinical characteristics of the disease are unknown in women.

\section{Epidemiology}

In England, where nongonococcal urethritis has been a reportable disease since 1951, there has been a documented tenfold increase in incidence from 1951 to $1978 .^{1,2}$ By comparison, gonorrhea has increased slightly more than four times in incidence during the same period. Both gonococcal and nongonococcal urethritis are seen primarily between the ages of sixteen and twenty-six, and are much more common in single patients, as opposed to those married or divorced. ${ }^{3}$ The incidence of nongonococcal urethritis is generally higher than that of gonococcal urethritis in students, whites, and upper middle-class populations. ${ }^{3,4}$

\section{Clinical Features}

Nongonococcal urethritis is characterized by a gradual onset of mild dysuria. Urethral or perineal itching, associated with urinary frequency, can also occur. Frequently there is a clear mucoid urethral discharge. This is in contradistinction to gonorrhea, where the abrupt onset of dysuria and purulent discharge is the rule. Examination of the midstream urine may be negative, although the first voided specimens in either case will show pyuria, generally without bacteriuria.

While the history and physical examination may be suggestive, the diagnosis of nongonococcal urethritis is made by excluding the presence of $\mathbf{N}$. gonorrhoeae on gram stain and culture of the urethral discharge. Jacobs and Kraus ${ }^{5}$ have demonstrated that a gram stain showing typical gram-negative intracellular diplococci correlated with culture positive for $\mathrm{N}$. gonorrhoeae in 98 per cent of cases. Similarly, if no gram-negative diplococci were seen on gram stain, 98 per cent of cultures were negative for $\mathrm{N}$. gonorrhoeae. ${ }^{5}$ Approximately 15 per cent of cases are nondiagnostic on gram stain. Clinical judgment along with culture results are needed to make the diagnosis in these cases.

\section{Etiology}

As mentioned, numerous causes for nongonococcal urethritis have been suggested. Recent studies have implicated Chlamydia 
trachomatis, Ureaplasma urealyticum (" $\mathrm{T}$ strain" mycoplasma), and Trichomonas vaginalis as etiologic agents.

Following family studies of infants with inclusion conjunctivitis, the ophthalmologist, Lindner, ${ }^{6}$ first connected C. trachomatis to nongonococcal urethritis in 1911. More recent studies have shown that $\mathrm{C}$. trachomatis is isolated from the urethra in 30 to 40 per cent of patients with nongonococcal urethritis and only 5 to 10 per cent of controls. ${ }^{7-10}$ The question remains whether $C$. trachomatis is truly a pathogenic organism or merely part of the urethral flora. Bowie et al. ${ }^{11}$ have performed serologic investigations which suggest $C$. trachomatis in the urethra is a significant infection. In their study, 100 per cent of 20 men with positive cultures for $C$. trachomatis were noted to have evidence of seroconversion; this is in contrast to 20 per cent of 39 men with negative cultures. Further evidence for the significance of the $\mathrm{C}$. trachomatis is that therapy directed specifically against it will cure nongonococcal urethritis in 80 per cent of cases. Definitive proof of the role of $C$. trachomatis awaits fulfillment of Koch's postulates, including experimental urethral inoculations. This has been attempted on a small scale in baboons, but the results are inconclusive. ${ }^{12}$ In summary, C. trachomatis has not been proved to be an etiologic agent in nongonococcal urethritis; but the evidence is suggestive.

McCormack et al. ${ }^{13}$ recently have presented an extensive review of the role of genital mycoplasmas in nongonococcal urethritis. They note eight controlled studies which support the role of T-mycoplasma in nongonococcal urethritis. They also note six equally valid controlled studies which show no association between T-mycoplasma and nongonococcal urethritis. In addition, they were unable to find any studies which document antibody against $\mathrm{T}$-mycoplasma in large numbers of patients with nongonococcal urethritis. Artificial urethral inoculation has not been done, however evidence at this time is against a role for these urganisms in nongonococcal urethritis.

T. vaginalis is rarely found in men, consequently the finding of this organism in 6 per cent of patients with nongonococcal urethritis is significant. ${ }^{10}$ Because of its low incidence, little research has been done on its role in nongonococcal urethritis.

While infection with $\mathrm{C}$. trachomatis or $\mathrm{T}$. vaginalis may cause nongonococcal urethritis in
40 to 50 per cent of cases, the others remain unexplained at this time. Scientific evidence supporting the role of trauma, allergy, or infection with a viral or fungal agent is lacking.

\section{Treatment}

\section{Nongonococcal urethritis}

Although most studies suggest a beneficial effect of tetracycline in nongonococcal urethritis, ${ }^{14,15}$ there is some evidence to support the anecdotal impression that many cases resolve spontaneously. ${ }^{16}$ All these studies, however, have serious methodologic shortcomings. Only in the study by Holmes, Johnson, and Floyd ${ }^{17}$ could care be taken to insure that medication was taken as prescribed. Since it is thought that nongonococcal urethritis is not transmitted between homosexuals, and since this study was performed on an aircraft carrier at sea, sexual reexposure was not possible. Failure of therapy can then be assumed to be recurrence and not reinfection. In this double-blind controlled study, successful treatment was achieved in 90 per cent of those treated for seven days, 65 per cent of those treated for four days, and 14 per cent of those treated with placebo. Most clinicians now accept that antibiotic therapy with tetracycline hydrochloride $(1,500 \mathrm{mg}$. initially, then $500 \mathrm{mg}$. orally four times daily for seven days) will achieve clinical cure in 80 to 90 per cent of cases. Erythromycin or trimethoprimsulfamethoxazole can be used as alternative therapy. Penicillin, the treatment of choice for gonorrhea, is of no benefit in the treatment of nongonococcal urethritis.

\section{Postgonococcal urethritis}

After seemingly adequate treatment of gonococcal urethritis, 20 to 30 per cent of patients present with a clear mucoid discharge and mild dysuria, similar to nongonococcal urethritis. Urethral cultures of patients with gonorrhea reveal that $\mathrm{C}$. trachomatis is present in 17 to 32 per cent of cases. ${ }^{7,9,10}$ Follow-up reveals that in 81 per cent of these patients postgonococcal urethritis will develop, as opposed to 10 per cent of those patients with gonorrhea who are negative for $\mathrm{C}$. trachomatis. ${ }^{7}$ Treatment with tetracycline will eradicate the postgonococcal urethritis in most cases. ${ }^{10}$ These data suggest a simultaneous infection with $\mathrm{N}$. gonorrhoeae and the agent of nongonococcal urethritis. Holmes et al. ${ }^{18}$ suggest that in closely supervised or highly reliable patients, multiple 
doses of oral tetracycline may be the drug of choice for the treatment of gonorrhea. In most cases, though, gonorrhea should be treated with parenteral penicillin and postgonococcal urethritis should be treated as nongonococcal urethritis.

\section{Recurrent nongonococcal urethritis}

Those patients who repeatedly fail routine therapy for nongonococcal urethritis can be treated successfully, A thorough systematic approach is necessary, taking into account compliance, reinfection, unusual organisms, and the possibility that the initial diagnosis is incorrect. It is well-known that milk products must be avoided when taking tetracycline, since calcium ions will bind the tetracycline, preventing absorption. The avoidance of milk products and a regimen of four doses per day, makes patient compliance difficult. Adherence to the treatment program should be stressed, as inadequate therapy will lead to recurrence. The distinction between recurrence and reinfection is important. Bowie et al. ${ }^{11}$ have shown that 64 per cent of cultures from the cervix of sexual partners of men with $C$. trachomatis on urethral culture, will also show $\mathrm{C}$. trachomatis; this is in contrast to 5 per cent of controls. This justifies treating the patient and all sexual partners simultaneously, to prevent reinfection. In difficult cases, a search for other agents, e.g., T. vaginalis or Candida albicans, is occasionally rewarding. Since it is difficult to examine the urethral discharge, a check of the partner's cervical mucus for trichomonads or yeast is helpful. ${ }^{19}$ It has also been suggested that the trauma of repeated urethral "milking" may interfere with the host's ability to resolve the urethritis. ${ }^{19}$ Finally, the presence of a Cowper duct cyst or a urethral diverticulum can allow urinary accumulation and later "discharge" mimicking that of nongonococcal urethritis. This can be diagnosed easily on retrograde urethrogram.

There is the occasional patient with recurrent symptoms in whom no discharge is ever documented and no organic cause can be found. The diagnosis of psychogenic urethritis should be considered and appropriate therapy recommended.

\section{Complications}

In the past, nongonococcal urethritis has been considered a benign, selflimiting disease. ${ }^{20,21}$ Proof of its relationship with other diseases is difficult, since the cause of nongonococcal urethritis is itself uncertain. How- ever, recent data indicate it may be involved in epididymitis, pelvic inflammatory disease, and infantile pneumonia.

Heap $^{22}$ first reported a relationship between acute epididymitis and C. trachomatis. A more extensive study by Berger et al. ${ }^{23}$ confirms that finding. The symptoms and signs of nongonococcal urethritis should be sought in all cases of epididymitis, and perhaps "sterile" epididymitis should be treated with antimicrobials, in particular, tetracycline.

Knowing the propensity for cervical colonization of female cohorts of patients with nongonococcal urethritis, there is a theoretical basis for finding disease caused by $\mathrm{C}$. trachomatis in women and newborn infants. ${ }^{11}$ Recently, Mårdh et al. ${ }^{24}$ and Eilard et al. ${ }^{25}$ have isolated C. trachomatis from patients with acute salpingitis. Likewise, Beem and Saxon ${ }^{26}$ have associated C. trachomatis with a pneumonia syndrome in newborns. As mentioned previously, Lindner ${ }^{6}$ associated nongonococcal urethritis with inclusion conjunctivitis in the newborn in 1911.

\section{Summary}

Nongonococcal urethritis is characterized by slow onset of mild dysuria in a patient with a watery urethral discharge. Although a gram stain of the discharge generally reveals no organisms, the disease is thought to be infectious, with $C$. trachomatis being the etiologic agent in many cases. The occurrence of this disease after adequate treatment of gonorrhea is believed to represent simultaneous infection with $\mathrm{N}$. gonorrhoeae and the etiologic agent for nongonococcal urethritis. Therapy with tetracycline is recommended for both nongonococcal and postgonococcal urethritis to alleviate symptoms and avoid complications.

Ann Arbor, Michigan 48109

\section{References}

1. Wiesner PJ: Selected aspects of the epidemiology of nongonococcal urethritis, in Hobson and Holmes (Eds.): Nongonococcal Urethritis and Related Infections, Washington, D.C., American Society for Microbiology, 1977, p. 9.

2. Academic Department of Genitourinary Medicine of the Middlesex Hospital Medical School et al.: Sexually transmitted disease surveillance 1978, Br. Med. I. 2: 1375 (1979).

3. Volk J, and Kraus SJ: Nongonococcal urethritis, Arch. Intern. Med. 134: 511 (1974).

4. McChesney JA, et al: Acute urethritis in male college students, JAMA 226: 37 (1973).

5. Jacobs NF, and Kraus SJ: Gonococcal and nongonococcal urethritis in men, Ann. Intern. Med. 82: 7 (1975).

6. Lindner $\mathrm{K}$ : Gonoblennorrhoe, einschlussblenorrhoe und trachoma, Albrect von Graetes Arch. Ophthalmol. 78: 380 (1911). 
7. Richmond SJ, Hilton AL, and Clarke SKR: Role of chlamydia subgroup $\mathrm{A}$ in non-gonococcal and post-gonococcal urethritis, $\mathrm{Br}$. J. Vener. Dis. 48: 429 (1972).

8. Oriel JD, et al: Isolation of chlamydia from patients with non-specific genital infection, ibid. 48: 429 (1972).

9. Holmes KK, et al: Etiology of non-gonococcal urethritis, N. Engl. J. Med. 292: 1199 (1975).

10. Jacobs NF, Arwin ES, and Kraus SI: Nongonococcal urethritis: the role of Chlamydia trachomatis, Ann. Intern. Med. 86: 314 (1977).

11. Bowie WR, et al: Nongonococcal urethritis: roles of chlamydia and ureaplasma, J. Clin. Invest. 59: 35 (1977).

12. DiGiacomo RF, et al: Chlamydial infection of the male baboon urethra, Br. J. Vener. Dis. 51: 310 (1975).

13. McCormack WM, et al: The genital mycoplasmas, $\mathrm{N}$. Engl. J. Med. 288: 78 (1973).

14. Willcox RR: Tetracycline hydrochloride in the treatment of nongonococcal urethritis, Antibiot. Med. 1: 142 (1955).

15. Doyle JO, Gill AJ, and Laird SM: Treatment of nongonococcal urethritis, Br. J. Vener. Dis. 33: 100 (1957).

16. Laidig CE, and Berg P: Effect of antibiotics on the course of nongonococcal urethritis, J. Urol. 77: 457 (1957).
17. Holmes KK, Johnson DW, and Floyd TM: Double-blind comparison of tetracycline hydrochloride and placebo in treatment of non-gonococcal urethritis, JAMA 202: 474 (1967).

18. Holmes $\mathrm{KK}$, et al: Observations on the incidence, etiology and treatment of post-gonococcul urethritis syndrome, ibid. 202 467 (1967).

19. Kaufman RE, and Wiesner PJ: Nonspecific urethritis, N. Engl. J. Med. 291: 1175 (1974).

20. Prebble EE: Treatment of nongonococcal urethritis, Br. J. Vener. Dis. 33: 43 (1957).

21. Fowler W: In discussion, ibid. ${ }^{20}$

22. Heap G: Acute epididymitis attributable to chlamydial infection - preliminary report, Med. J. Aust. 1: 718 (1975),

23. Berger RE, et al: Chlamydia trachomatis as a cause of acute "idiopathic" epididymitis, N. Engl. J. Med. 298: 30 (1978).

24. Mårdh P-A, et al: Chlamydia trachomatis infection in patients with acute salpingitis, ibid. 296: 1377 (1977).

25. Eilard $\mathrm{T}$, et al: Isolation of chlamydia in acute salpingitis, Scand. J. Infect. Dis. (Suppl. 9) 82 (1976).

26. Beem MO, and Saxon EM: Respiratory-tract colonization and a distinctive pneumonia syndrome in infants infected with Chlamydia trachomatis, N. Engl. J. Med. 296: 306 (1977). 